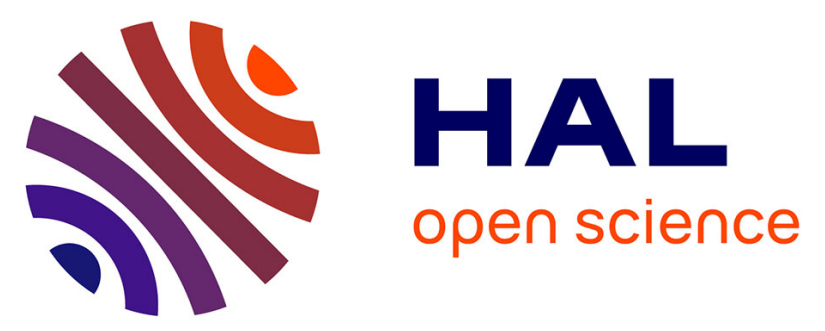

\title{
Low prevalence of colonoscopic surveillance of inflammatory bowel disease patients with longstanding extensive colitis: a clinical practice survey nested in the CESAME cohort
}

Ariane Vienne, Tabassome Simon, Jacques Cosnes, Clotilde Baudry, Yoram

Bouhnik, Jean-Claude Soule, Stanislas Chaussade, Philippe Marteau, Raymond Jian, Jean-Charles Delchier, et al.

\section{- To cite this version:}

Ariane Vienne, Tabassome Simon, Jacques Cosnes, Clotilde Baudry, Yoram Bouhnik, et al.. Low prevalence of colonoscopic surveillance of inflammatory bowel disease patients with longstanding extensive colitis: a clinical practice survey nested in the CESAME cohort. Alimentary Pharmacology and Therapeutics, 2011, 34 (2), pp.188. 10.1111/j.1365-2036.2011.04711.x . hal-00645192

\section{HAL Id: hal-00645192 \\ https://hal.science/hal-00645192}

Submitted on 27 Nov 2011

HAL is a multi-disciplinary open access archive for the deposit and dissemination of scientific research documents, whether they are published or not. The documents may come from teaching and research institutions in France or abroad, or from public or private research centers.
L'archive ouverte pluridisciplinaire $\mathbf{H A L}$, est destinée au dépôt et à la diffusion de documents scientifiques de niveau recherche, publiés ou non, émanant des établissements d'enseignement et de recherche français ou étrangers, des laboratoires publics ou privés. 


\begin{tabular}{l}
\hline Alimentary Pharmacology \\
\hline \& Therapeutics \\
\hline
\end{tabular}

\section{Low prevalence of colonoscopic surveillance of inflammatory bowel disease patients with longstanding extensive colitis: a clinical practice survey nested in the CESAME cohort}

\begin{tabular}{|c|c|}
\hline Journal: & Alimentary Pharmacology \& Therapeutics \\
\hline Manuscript ID: & APT-0158-2011.R1 \\
\hline Wiley - Manuscript type: & Original Scientific Paper \\
\hline $\begin{array}{r}\text { Date Submitted by the } \\
\text { Author: }\end{array}$ & 05-Apr-2011 \\
\hline Complete List of Authors: & $\begin{array}{l}\text { VIENNE, Ariane; Cochin Hospital, Gastroenterology } \\
\text { Simon, Tabassome; Saint Antoine Hospital, Pharmacology, URCEST } \\
\text { Cosnes, Jacques; Saint Antoine Hospital, Gastroenterology } \\
\text { Baudry, Clotilde; Saint-Louis Hospital, Gastroenterology } \\
\text { Bouhnik, Yoram; AP-HP Hôpital Beaujon, Pole des maladies de } \\
\text { l'appareil digestif, gastroentérologie et assistance nutritive } \\
\text { SOULE, Jean-Claude; AP-HP, Hôpital Bichat, Service d'Hépato- } \\
\text { Gastroentérologie } \\
\text { Chaussade, Stanislas; Cochin Hospital, Gastroenterology } \\
\text { Marteau, Philippe; Lariboisière hospital, gastroenterology } \\
\text { JIAN, Raymond; AP-HP HEGP, Gastroenterology } \\
\text { Delchier, Jean-Charles; Hôpital Henri-Mondor, Hepato- } \\
\text { Gastroenterology } \\
\text { COFFIN, Benoit; AP-HP Hopital Louis Mourier, Gastroenterology } \\
\text { Unit; Université Denis Diderot-Paris 7 } \\
\text { Admane, Hakeem; Saint Antoine Hospital, Pharmacology, URCEST } \\
\text { Carrat, Fabrice; Saint Antoine Hospital, Unit of public health } \\
\text { Drouet, Elodie; Saint Antoine Hospital, Pharmacology, URCEST } \\
\text { Beaugerie, Laurent; Hôpital Saint-Antoine, Service de Gastro- } \\
\text { entérologie et Nutrition }\end{array}$ \\
\hline Keywords: & $\begin{array}{l}\text { Inflammatory bowel disease }<\text { Disease-based, Colonoscopy }< \\
\text { Topics, Compliance / adherence }<\text { Topics, Colorectal cancer }< \\
\text { Disease-based }\end{array}$ \\
\hline
\end{tabular}

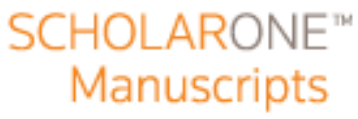




\section{Low prevalence of colonoscopic surveillance of inflammatory bowel disease patients with longstanding extensive colitis: a clinical practice survey nested in the CESAME cohort}

Running tittle: Colonoscopic surveillance in IBD

Ariane Vienne, ${ }^{1}$ Tabassome Simon, ${ }^{2}$ Jacques Cosnes, ${ }^{1}$ Clotilde Baudry, ${ }^{3}$ Yoram Bouhnik, ${ }^{4}$ Jean Claude Soulé, ${ }^{5}$ Stanislas Chaussade, ${ }^{6}$ Philippe Marteau, ${ }^{7}$ Raymond Jian, ${ }^{8}$ Jean-Charles Delchier, ${ }^{9}$ Benoît Coffin, ${ }^{10}$ Hakeem Admane, ${ }^{2}$ Fabrice Carrat, ${ }^{11}$ Elodie Drouet, ${ }^{2}$ and Laurent Beaugerie, ${ }^{3}$

\footnotetext{
${ }^{1}$ Department of Gastroenterology, AP-HP, Saint-Antoine Hospital F-75012 and UPMC Univ Paris 06 F-75005, Paris, France; ${ }^{2}$ Department of Pharmacology, URC-EST, APHP, GH-STARTT, and UPMC Univ Paris 06, Paris, France; ${ }^{3}$ Department of Gastroenterology, AP-HP, Saint-Louis Hospital F-75010 and Denis Diderot University, Paris 7, Paris, France; ${ }^{4}$ Department of Gastroenterology, AP-HP, Beaujon Hospital F-92110 and Denis Diderot University, Paris 7, Paris, France; ${ }^{5}$ Department of Gastroenterology, AP-HP, Bichat Hospital F-75018 and Denis Diderot University, Paris 7, Paris, France; ${ }^{6}$ Department of gastroenterology, AP-HP, Cochin Hospital F-75005 and Université Paris Descartes University, Paris, France; ${ }^{7}$ Department of Gastroenterology, AP-HP, Lariboisière Hospital F-75010 and Denis Diderot University, Paris 7, Paris, France; ${ }^{8}$ Department of gastroenterology, AP-HP, Hôpital Européen Georges Pompidou F-75015 and Université Paris Descartes, Paris, France; ${ }^{9}$ Department of Gastroenterology, AP-HP, Henri Mondor Hospital and Univ Paris12 F-94000, Créteil, France; ${ }^{10}$ Department of Gastroenterology, AP-HP, Louis Mourier Hospital, Colombes, F-92700 and Denis Diderot University, Paris 7, Paris, France; ${ }^{11}$ Unit of Public Health, AP-HP, Saint-Antoine Hospital F-75012, INSERM UMR-S 707 F-75012 and UMR-S 707 UPMC Univ Paris 06 F-75012, Paris, France
}

Correspondence: Professor Laurent Beaugerie

Service de Gastroentérologie et Nutrition, Hôpital Saint-Antoine, 184 rue du faubourg Saint-Antoine, 75571 Paris CEDEX 12, France.

Tel: 331492831 71, Fax: 33149283188 E-mail: laurent.beaugerie@sat.aphp.fr 


\title{
Funding
}

This clinical practice study nested in the CESAME project was supported by an unconditional grant from Institut National du Cancer (INCa). The CESAME project was supported by grants from Programme Hospitalier de Recherche Clinique National (AOM05157), Association François Aupetit, Délégation Inter-régionale de la Recherche clinique lle de France-Assistance Publique Hôpitaux de Paris (AP-HP), Ligue contre le Cancer, and Fonds de Recherche de la Société Nationale Française de Gastro-entérologie.

All the authors have nothing to disclose in relation with this work

\begin{abstract}
AV, TS, FC, ED, HA and LB were involved in study concept and design. AV and LB were involved in drafting of the manuscript. All the authors were involved in acquisition and interpretation of data, and critical revision of the manuscript.
\end{abstract}

\section{Abbreviations}

5-ASA,5-amino-salicylates; CRC, Colorectal Cancer; IBD, Inflammatory Bowel Disease; UC, Ulcerative colitis

Crohn's disease

Abstract count word: 250

Acknowledgments

The authors wish to honor the memory of Marc Lémann who actively participated in the study 


\section{Summary}

Background: Surveillance colonoscopy is recommended for inflammatory bowel disease (IBD) patients with longstanding extensive colitis (LEC).

Aims: To assess modalities and results of colonoscopic surveillance in a subset of CESAME cohort patients at high risk of colorectal cancer (CRC) and followed in university French hospitals.

Methods: Among 910 eligible patients with more than a 7-year history of extensive colitis at CESAME enrolment, 685 patients completed a questionnaire on surveillance colonoscopy and 102 were excluded because of prior proctocolectomy. Finally, 583 patients provided information spanning a median period of 41 months (IQR 38-43) between cohort enrolment and the end of follow-up. Details of the colonoscopic procedures and histological findings were obtained for 440 colonoscopies in 270 patients.

Results: Only 53.5\% ( $n=312)$ of the patients with LEC had at least one surveillance colonoscopy during the study period, with marked variations across the 9 participating centres $(27.3 \%$ to $70.0 \%, \mathrm{p}=<0.0001)$. Surveillance rate was significantly lower in Crohn's colitis than in ulcerative colitis (UC) $(47.6 \%$ vs $68.5 \%$, $p=<0.0001$ ). Independent predictors of colonoscopic surveillance were male sex, UC IBD subtype, longer disease duration, previous history of CRC, and disease management in a centre with large IBD population. Random biopsies, targeted biopsies and chromoendoscopy were performed during respectively $70.7 \%, 26.6$ and $30.0 \%$ of surveillance colonoscopies. Two cases of high-grade dysplasia were detected in patients undergoing colonoscopic surveillance. Two advanced-stage CRC were diagnosed in patients who did not have colonosocopic surveillance. 
Conclusions: Colonoscopic surveillance rate is low in IBD patients with longstanding extensive colitis.

\section{Key words:}

Inflammatory bowel disease; Colorectal cancer; Colonoscopic surveillance 
Patients with longstanding extensive ulcerative colitis (UC) are at high risk of developing colonic epithelial dysplasia and carcinoma. ${ }^{1}$ Growing evidence suggests that the same is true of patients with longstanding extensive Crohn's colitis. ${ }^{2,3}$ Two interventions are currently used in an attempt to reduce mortality by colorectal cancer (CRC) in these patients, namely colonoscopic surveillance and chemoprevention with oral 5-aminosalicylates (5-ASA). Colonoscopic surveillance has not been shown to reduce mortality among patients with extensive colitis, but it does tend to allow cancer to be detected at an earlier stage, thereby improving the prognosis. ${ }^{4}$ There is good international agreement that patients with inflammatory bowel disease (IBD) and extensive colitis should have surveillance colonoscopy every 1-3 years, generally starting 7-10 years after IBD onset, or from IBD diagnosis in patients with associated primary sclerosing cholangitis. ${ }^{4-11}$ Extensive UC is defined on the basis of the cumulative macroscopic or microscopic extent of the disease proximal to the splenic flexure. ${ }^{7,} 12$ Extensive Crohn's colitis is arbitrarily defined as cumulative endoscopic involvement of more than one-third of the colon. ${ }^{2,7}$ Surveillance colonoscopy should ideally be performed outside periods of disease activity and with good bowel cleansing, and should include multiple random biopsies or targeted biopsies after chromoscopy.

Despite this solid consensus, questionnaire-based studies have revealed suboptimal awareness and implementation of guidelines by gastroenterologists in various parts of the world. ${ }^{13,14}$ In addition, the degree of information, acceptance and adherence to surveillance programs among patients at risk is unknown. Population-based studies have shown poor implementation of endoscopic surveillance among IBD patients at very high risk of colorectal cancer because of associated primary sclerosing cholangitis. ${ }^{15} \mathrm{~A}$ low prevalence of colorectal surveillance of patients with longstanding 
UC belonging to an integrated health care delivery system was recently reported, ${ }^{16}$ but there are no published reports of the implementation and yield of surveillance colonoscopy in patients with either UC or Crohn's disease who are at a high risk of colorectal cancer because of longstanding extensive colitis. We therefore conducted an ancillary study nested in the CESAME project in order to assess the implementation, modalities and yield of surveillance colonoscopy in a cohort of IBD patients with longstanding extensive colitis. We also compared the incidence of advanced-stage neoplasias in surveyed and non-surveyed patients, and examined the relative proportions of patients receiving surveillance colonoscopy and/or chemoprevention with 5-ASA.

\section{METHODS}

\section{Study design}

The study was nested in the CESAME project, which is described in detail elsewhere. ${ }^{17}$ In brief, 19486 IBD patients (1159 with Crohn's disease and 7727 with UC or unclassified IBD) were enrolled between May 2004 and May 2005 in a French nationwide cohort by 680 gastroenterologists, who reported all incident high-grade dysplasias, cancers and deaths up to 31 December 2007. At enrolment, the gastroenterologists recorded the patient's age, gender, IBD subtype, year of diagnosis and cumulative extent of disease. Cumulative involvement of the colon in UC and Crohn's colitis was arbitrarily categorized as extensive when the cumulative percentage of the colonic surface ever involved, estimated by the investigating gastroenterologist, exceeded 50\%. CESAME patients meeting this criterion also fulfilled the definition of extensive colitis stated in surveillance colonoscopy guidelines. $^{2,7,12}$ 
This nested ancillary study was initiated in September 2008. Patients enrolled in the CESAME cohort were eligible for this study if they belonged to the CESAME cohort and met the following criteria: IBD duration longer than 7 years at the outset of the CESAME observation period; extensive colitis at entry; and enrolment to the cohort by a gastroenterologist working full-time in one of the 9 Paris area university hospital gastroenterology units participating in the CESAME project. All 910 patients who met these criteria were sent a questionnaire covering the following items: previous history and type of any colectomy, current treatment with corticosteroids, thiopurines, methotrexate or TNF antagonists, duration and modalities of any treatment with oral 5-ASA; and number of coloscopies between May 2004 (first inclusions in the CESAME cohort) and 31 December 2007. Patients who had at least one colonoscopy were asked to complete an additional sheet for each colonoscopy, covering where the colonoscopy was performed and the medical indication (flare, disease assessment before a change of treatment, or cancer screening). The questionnaire was accompanied by an explanatory letter and a pre-paid envelope to return either the questionnaire or a refusal form. Patients who did not return the completed questionnaire or the refusal form after one month were contacted by telephone. If during the conversation they consented to participate, they were interviewed by phone on the same items as those contained in the written questionnaire. The protocol was approved by Comité Consultatif sur le Traitement de I'Information en matière de Recherche dans le domaine de la Santé, and the study was authorized ( $n^{\circ}$ DR-2010-019) by Comission Nationale de I'Informatique et des Libertés. 


\section{Patient selection and analysis of colonoscopy reports}

Among the 910 patients eligible for the study, 10 died before the questionnaires were sent out, and 34 had no known address (fig. 1). Eight hundred and sixty-six questionnaires were sent out. Nineteen patients refused to participate and 162 did not respond by mail or by phone. A total of 685 patients answered the questionnaire, representing a $79 \%$ participation rate. There was no statistically significant difference in gender, age or the IBD subtype between patients who answered the questionnaire and those who did not. Among the 685 patients who answered the questionnaire, 102 were excluded because of a prior history of proctocolectomy. The final study population consisted of 583 patients.

Among the 312 patients who mentioned at least one surveillance colonoscopy in the questionnaire, 282 had their examination performed in the endoscopy department of one of the nine participating centres. We were able to obtain a copy of the endoscopic and histological reports of 440 colonoscopies performed in 270 patients. A standardized report form was used to collect the following details: quality of bowel preparation (categorized as satisfactory or unsatisfactory); thoroughness of exploration of the colonic segments to be explored; presence of macroscopic inflammatory lesions (at least frank erythema); use of chromoscopy; and collection of random biopsies (at least 4 per segment) and/or targeted biopsies.

We were thus able to validate the information given by the patients on the number, indications and modalities of their colonoscopies, and found an overall concordance exceeding $90 \%$ for each item. In case of disagreement we kept the information contained in the endoscopic reports. 


\section{Data analysis}

Taking into account the length of the study period (median 41 months, minimum 31 months) and published guidelines on surveillance colonoscopy, all the patients with longstanding extensive colitis should have had at least one surveillance colonoscopy, i.e. a dedicated cancer screening colonoscopy, during the study period. Patients who had at least one surveillance colonoscopy during the study period formed the "surveyed" population, and the remaining patients the "non-surveyed" population. Patients prescribed chemoprevention with 5-ASA during the study period formed the population of patients exposed to oral 5-ASA. Patients with unclassified IBD were pooled with UC patients for analysis.

Statview ${ }^{\circledR}$ statistical software (version 5.0, SAS Institute Inc., Cary, NC) was used to analyse the data. Fisher's exact test was used to compare the proportions of surveyed and non-surveyed patients with each IBD subtype, and to identify a possible correlation between colonoscopic surveillance and 5-ASA chemoprevention. The Chi-square test was used to compare the proportions of surveyed patients across the study centres. The following 8 variables were tested as possible independent predictors of colonoscopic surveillance: gender; IBD subtype; age; disease duration; previous personal history of colorectal cancer; sustained? treatment with 5-ASA; the number of IBD patients followed per investigator; and the number of IBD patients followed per centre. The 4 continuous variables were dichotomized around the median. All 8 variables were first separately compared between surveyed and non-surveyed patients by using Fisher's exact test, then variables with $p$ values below 0.20 were entered in a multivariate logistic regression model using a backward stepwise procedure. The final step retained independent factors with $P$ values below 0.05 in a two-tailed test. 


\section{RESULTS \\ Overall surveillance rate and patients' baseline characteristics according to surveillance status}

Characteristics of the 583 patients who answered the questionnaire by mail $(n=351)$ or by phome $(n=232)$ and who had no history of proctocolectomy are shown in table 1. The surveyed population consisted of 310 patients (53.2\%) who had at least one surveillance colonoscopy during the study period (median 41, IQR 38-43). Respectively 165, 104, 33, 8 and 1 patients had 1,2, 3, 4 and 5 surveillance colonoscopies. One patient had 7 surveillance endoscopies during the study period, to monitor unifocal low-grade dysplasia.

\section{Factors influencing surveillance}

The monitoring rate was significantly higher among patients with UC or unclassified IBD than among patients with Crohn's disease $(68.5 \%$ versus $47.6 \%, \mathrm{p}<0.0001)$. Considering all IBD subtypes together, surveillance implementation varied widely across the study centres (27.3 to $70 \%, p<0.001$ (fig 2)). Independent predictors of surveillance (table 2) were male gender, UC, longer disease duration, a previous history of colorectal cancer, and management in a centre with a large IBD patient population.

\section{Colonoscopic procedures and pathology reports:}

We were able to analyze 440 reports of colonoscopies performed in 270 patients, along with the corresponding pathology reports. The quality of bowel preparation was specified in $82.7 \%$ of colonoscopy reports and was considered by the endoscopist as satisfactory and unsatisfactory in $83.8 \%$ and $16.2 \%$ of cases, respectively. Exploration of anatomically evaluable colonic segments was complete in $96.6 \%$ of 
cases. Endoscopic evidence of mild inflammation (frank erythema or multiple pseudopolyps) or active inflammation (ulceration) was mentioned in respectively $30.0 \%$ and $5.2 \%$ of reports. At least one biopsy was performed in $97.3 \%$ of procedures, and consisted of random biopsies (at least 4 biopsy samples per colonic segment), random biopsies plus targeted biopsies, or targeted biopsies alone, in respectively $72.6 \%, 26.5 \%$ and $0.9 \%$ of cases. Chromoendoscopy was performed during $30.0 \%$ of colonoscopies. The pathology reports mentioned the presence and absence of active microscopic inflammation and any type of dysplasia in respectively $94.7 \%$ and $77.7 \%$ of cases. Fourteen cases of flat low-grade dysplasia were found in 12 patients $(4.4 \%)$, of whom 5 were exposed to 5 -ASA at the time of diagnosis of dysplasia. Twelve adenoma-like masses with low-grade dysplasia were found in 11 patients $(4 \%)$, of whom 6 were exposed to 5-ASA at the time of diagnosis of dysplasia.

\section{Incident advanced-stage neoplasias}

Four patients in this ancillary study, all with Crohn's colitis, were diagnosed with advanced-stage colonic neoplasia during the study period: two advanced-stage colorectal cancers (T4NOM0 and T4N2M0) were diagnosed in non-surveyed patients. The first patient was a 26-year man with a 10-year history of extensive Crohn's colitis and the second a 30-year female with a 16-year history of extensive Crohn's colitis. Two cases of high-grade dysplasia were detected in two surveyed patients. The first patient was a 56-year man with a 10-year history of extensive Crohn's colitis and had a flat dysplasia. The second patient was a 31-year man with a 15-year history of extensive Crohn's colitis in whom a dysplasia-associated lesion or mass was diagnosed. After confirmation of dysplasia by a second independent pathologist, both 
patients underwent coloproctectomy. Colon cancer was found on the colectomy specimen of the first patient with flat high-grade dysplasia (stage T2NOM0). Highgrade dysplasia was confirmed on the colectomy specimen of the second patient with the dysplasia-associated lesion or mass, without additional advanced-stage neoplasia.

Correlation between colonoscopic surveillance and chemoprevention with 5ASA

Continuous oral 5-ASA was prescribed to $37.4 \%$ of the 583 patients during the study period. The distribution of patients who received colonoscopic surveillance and/or treatment with 5-ASA is shown in table 3 according to the IBD subtype. There was a significant link between surveillance and treatment with 5-ASA $(p=0.0001)$, with a trend towards being either both surveyed and treated with 5-ASA, or non-surveyed and untreated. When considering together the two types of IBD, one third of the patients escaped both to endoscopic surveillance and treatment with 5-ASA. 


\section{DISCUSSION}

We observed low implementation of endoscopic surveillance in a cohort of IBD patients at high risk of colorectal cancer and managed in French university hospitals. We also observed massive inter-centre variations and a large proportion of nonsurveyed patients: one-third of patients with ulcerative colitis and more than one-half of patients with Crohn's colitis were not surveyed. Some cases of advanced colorectal neoplasias were diagnosed in non-surveyed patients.

This study was initially based on a self-reporting patient questionnaire, with a potential memory bias, representing therefore two important potential methodological limitations of the work. However, the completion rate of the questionnaire was $79 \%$ ( $81 \%$ when including patients who responded that they refused to participate), which is in the upper range of patient questionnaire ratings. ${ }^{18}$ The secondary exclusion of $11 \%$ of the patients because of previous proctocolectomy, thus with no actual eligibility for surveillance, did not impact on the quality of the results. Regarding memory bias, it is very unlikely that patients did not remember that they underwent one or several colonoscopies during the previous three years. We had also the opportunity through the study of endoscopic reports to validate the information given by the patients on the number, indications and modalities of their colonoscopies, and found an overall concordance exceeding $90 \%$ for each item. Finally, in the first author's centre, analysis of the local endoscopic files showed that surveillance was substantially less frequent among patients who did not answer the questionnaire (data not shown), suggesting that our results likely overestimate the implementation of endoscopic surveillance. So the main result of our work (low prevalence of surveillance) would have been amplified in the case of full completion rate of the questionnaire. We obtained details on colonoscopy in only $82 \%$ of surveyed patients, 
but the main purpose of our study was not assess the yield of the surveillance according to colonoscopy quality, and the number of detected neoplasias was too low to properly assess the impact of different biopsy modalities or exposure to 5-ASA on the rate of detected lesions.

In comparison with previous reports on the prevalence of colonoscopic surveillance in IBD patients at risk for colorectal cancer, ${ }^{16}$ our study is the first to restrict the analysis to patients at highest risk (i.e. with longstanding extensive colitis), to simultaneously address the question patients with ulcerative colitis and Crohn's disease, and to give the data on incident colorectal cancers in surveyed and non-surveyed patients.

Until now, information on gastroenterologists' adherence to international guidelines on endoscopic surveillance of IBD patients at risk of colorectal cancer, and on the management of dysplasia, has mainly been based on gastroenterologists' own estimates. $5,14,19,20$ The results of these studies showed that knowledge and understanding of the pathogenesis and management of IBD-associated colorectal neoplasias was unsatisfactory, but almost all the interviewed gastroenterologists declared that they performed endoscopic surveillance in the majority of their IBD patients at risk. Similarly, a clinical practice survey of patients already enrolled in surveillance programs in a tertiary care centre suggested good implementation of relevant guidelines. ${ }^{21}$

In order to obtain a more realistic view of the situation, we assessed the implementation of surveillance colonoscopy by adopting an at-risk population-based approach. Endoscopic surveillance has previously been shown to be suboptimal in a subgroup of IBD patients at very high risk of colorectal cancer due to associated primary sclerosing cholangitis. ${ }^{15}$ Likewise, a low rate of surveillance colonoscopy was 
found in North California patients with at least an 8-year history of UC and belonging to an integrated healthcare delivery organization. ${ }^{16}$

We based our study on the CESAME observational cohort, selecting patients at high risk of colorectal cancer and managed in 9 university hospitals in the Paris area. Implementation of endoscopic surveillance was found to be suboptimal, particularly in Crohn's disease patients, even though all the participating centres belong to GETAID and are therefore involved in promoting IBD education.

This incomplete endoscopic surveillance may be due to factors related to the patients and/or their physicians. Patients may be reluctant to participate in surveillance programs because they consider endoscopy to be unpleasant and risky, but UC patients undergoing surveillance did not express increased anxiety or general health impairment compared to a control population of UC patients. ${ }^{22}$ It is crucial to inform IBD patients of the risk of $\mathrm{CRC}$ and the modalities and expected results of surveillance. A survey conducted in the late 1990s suggested that patients were adequately informed on the risk of colorectal cancer but not on the effectiveness and modalities of surveillance programs, ${ }^{23}$ including the safety of colonoscopy. ${ }^{24}$ The massive inter-centre variations observed in our study point rather to a role of physician-related factors in suboptimal surveillance, and particularly poor awareness of the benefits of surveillance.

Interestingly, the surveillance rate was higher among males than females in our study, while a similar non-significant trend towards a better surveillance in males was reported in the study by Velayos et al. ${ }^{16}$ We have no explanation for that. In studies assessing the predictors of participation in screening programs for sporadic colorectal cancer, an increased prevalence of sigmoidoscopic surveillance ${ }^{25}$ and a trend 
towards a preference for endoscopy rather than for faecal tests ${ }^{26}$ were also reported in males.

More than half the patients with extensive Crohn's colitis were not adequately surveyed, whereas all the incident colorectal cancers were diagnosed in patients with Crohn's disease. Inflammation-related cancers arising in Crohn's colitis and UC have a similar distribution and histology (synchronous, right-sided, colloid contingent), and tend to be associated with coexisting foci of flat dysplasia in both settings. ${ }^{27,} 28$ Similar incidence rates of colorectal cancer have also been reported in UC and Crohn's colitis, ${ }^{27-30}$ although this feature was restricted in some referral centre cohorts of patients wiith Crohn's disease to those with UC-like lesions. ${ }^{31}$ In the CESAME cohort, the rates of excess colorectal cancer were similar in UC and Crohn's disease patients with longstanding extensive colitis. ${ }^{3}$ Thus, there is no theoretical reason to adapt endoscopic surveillance to the IBD subtype. Published surveillance guidelines refer currently to IBD colitis ${ }^{5-8,10}$ or UC alone, ${ }^{9}$ but there are no statements on colonoscopic surveillance in the most recent guidelines restricted to Crohn's disease. ${ }^{32}$ Second, the definition of extensive Crohn's colitis ${ }^{2,7}$ is not as consensual as that of extensive UC and does not appear in the Montreal classification. Finally, it may be more difficult to appreciate the cumulative percentage of inflamed mucosa in multifocal Crohn's colitis than in UC-like Crohn's colitis or UC.

Chemoprevention is another approach to reducing the risk of colorectal cancer in patients at risk, that has been considered by some authors as an alternative to surveillance, ${ }^{33}$ but we found that respectively $20 \%$ and $40 \%$ of UC and Crohn's patients at risk escaped both control measures. The efficacy of treatment with 5-ASA is controversial in IBD patients at risk, and especially those with Crohn's disease, although the cost-effectiveness of combined methods has been recently estimated. ${ }^{34}$ 
Whatever the final position of the gastroenterological community, the suboptimal and highly variable implementation of both control methods observed here in real-life practice is unacceptable and calls for urgent corrective measures. In addition to better education of gastroenterologists and patients, elaboration of specific guidelines in Crohn's disease, systematic mailing proposal for colonoscopic surveillance to patients at risk, and greater implication of patient associations and health authorities could be considered. 


\section{Figure legends}

Figure 1. Flow chart

Figure 2. Proportion of IBD patients undergoing colonoscopic surveillance according to IBD subtype (UC, ulcerative colitis; IBDU, IBD unclassified) and study centre 


\section{References}

1. Eaden JA, Abrams KR, Mayberry JF. The risk of colorectal cancer in ulcerative colitis: a meta-analysis. Gut 2001;48:526-35.

2. Friedman S, Rubin PH, Bodian C, et al. Screening and surveillance colonoscopy in chronic Crohn's colitis: results of a surveillance program spanning 25 years. Clin Gastroenterol Hepatol 2008;6:993-8.

3. Beaugerie L, Seksik P, Bouvier AM, et al. Thiopurine Therapy Is Associated with a Three-Fold Decrease in the Incidence of Advanced Colorectal Neoplasia in IBD Patients with Longstanding Extensive Colitis: Results from the CESAME Cohort. Gastroenterology 2009.;136:A-54.

4. Collins PD, Mpofu C, Watson AJ, et al. Strategies for detecting colon cancer and/or dysplasia in patients with inflammatory bowel disease. Cochrane Database Syst Rev 2006:CD000279.

5. Eaden JA, Mayberry JF. Guidelines for screening and surveillance of asymptomatic colorectal cancer in patients with inflammatory bowel disease. Gut 2002;51 Suppl 5:V10-2.

6. Winawer S, Fletcher R, Rex D, et al. Colorectal cancer screening and surveillance: clinical guidelines and rationale-Update based on new evidence. Gastroenterology 2003;124:544-60.

7. Itzkowitz SH, Present DH. Consensus conference: Colorectal cancer screening and surveillance in inflammatory bowel disease. Inflamm Bowel Dis 2005;11:314-21.

8. Kornbluth A, Sachar DB. Ulcerative colitis practice guidelines in adults (update): American College of Gastroenterology, Practice Parameters Committee. Am J Gastroenterol 2004;99:1371-85.

9. Biancone L, Michetti P, Travis SP, et al. European evidence based consensus on the management of Ulcerative Colitis: special situations. Journal of Crohn's and Colitis 2008;2:63-92.

10. Cairns SR, Scholefield JH, Steele RJ, et al. Guidelines for colorectal cancer screening and surveillance in moderate and high risk groups (update from 2002). Gut 2010;59:666-89.

11. Farraye FA, Odze RD, Eaden J, et al. AGA medical position statement on the diagnosis and management of colorectal neoplasia in inflammatory bowel disease. Gastroenterology 2010;138:738-45.

12. Satsangi J, Silverberg MS, Vermeire S, et al. The Montreal classification of inflammatory bowel disease: controversies, consensus, and implications. Gut 2006;55:749-53.

13. Eaden JA, Ward BA, Mayberry JF. How gastroenterologists screen for colonic cancer in ulcerative colitis: an analysis of performance. Gastrointest Endosc 2000;51:123-8.

14. Gearry RB, Wakeman CJ, Barclay ML, et al. Surveillance for dysplasia in patients with inflammatory bowel disease: a national survey of colonoscopic practice in New Zealand. Dis Colon Rectum 2004;47:314-22.

15. Kaplan GG, Heitman SJ, Hilsden RJ, et al. Population-based analysis of practices and costs of surveillance for colonic dysplasia in patients with primary sclerosing cholangitis and colitis. Inflamm Bowel Dis 2007;13:1401-7.

16. Velayos FS, Liu L, Lewis JD, et al. Prevalence of colorectal cancer surveillance for ulcerative colitis in an integrated health care delivery system. Gastroenterology 2010;139:1511-8.

17. Beaugerie L, Brousse N, Bouvier AM, et al. Lymphoproliferative disorders in patients receiving thiopurines for inflammatory bowel disease: a prospective observational cohort study. Lancet 2009;374:1617-25.

18. Richards SH, Campbell JL, Dickens A. Does the method of administration influence the UK GMC patient questionnaire ratings? Prim Health Care Res Dev 2011;12:6878. 
19. van Rijn AF, Fockens P, Siersema PD, et al. Adherence to surveillance guidelines for dysplasia and colorectal carcinoma in ulcerative and Crohn's colitis patients in the Netherlands. World J Gastroenterol 2009;15:226-30.

20. Thomas T, Nair P, Dronfield MW, et al. Management of low and high-grade dysplasia in inflammatory bowel disease: the gastroenterologists' perspective and current practice in the United Kingdom. Eur J Gastroenterol Hepatol 2005;17:1317-24.

21. Kottachchi D, Yung D, Marshall JK. Adherence to guidelines for surveillance colonoscopy in patients with ulcerative colitis at a Canadian quaternary care hospital. Can J Gastroenterol 2009;23:613-7.

22. Oxelmark L, Nordstrom G, Sjoqvist U, et al. Anxiety, functional health status, and coping ability in patients with ulcerative colitis who are undergoing colonoscopic surveillance. Inflamm Bowel Dis 2004;10:612-7.

23. Robinson RJ, Hart AR, Mayberry JF. Cancer surveillance in ulcerative colitis: a survey of patients' knowledge. Endoscopy 1996;28:761-2.

24. Koobatian GJ, Choi PM. Safety of surveillance colonoscopy in long-standing ulcerative colitis. Am J Gastroenterol 1994;89:1472-5.

25. Eloubeidi MA, Wallace MB, Desmond R, et al. Female gender and other factors predictive of a limited screening flexible sigmoidoscopy examination for colorectal cancer. Am J Gastroenterol 2003;98:1634-9.

26. Wong MC, Tsoi KK, Ng SS, et al. A comparison of the acceptance of immunochemical faecal occult blood test and colonoscopy in colorectal cancer screening: a prospective study among Chinese. Aliment Pharmacol Ther 2010;32:7482.

27. Choi PM, Zelig MP. Similarity of colorectal cancer in Crohn's disease and ulcerative colitis: implications for carcinogenesis and prevention. Gut 1994;35:950-4.

28. Svrcek M, Cosnes J, Beaugerie L, et al. Colorectal neoplasia in Crohn's colitis: a retrospective comparative study with ulcerative colitis. Histopathology 2007;50:57483.

29. Ekbom A, Helmick C, Zack M, et al. Ulcerative colitis and colorectal cancer. A population-based study. N Engl J Med 1990;323:1228-33.

30. Ekbom A, Helmick C, Zack M, et al. Increased risk of large-bowel cancer in Crohn's disease with colonic involvement. Lancet 1990;336:357-9.

31. Bergeron V, Vienne A, Sokol H, et al. Risk Factors for Neoplasia in Inflammatory Bowel Disease Patients With Pancolitis. Am J Gastroenterol 2010:advance online publication, 15 June 2010; doi: 10.1038/ajg.2010.248.

32. Van Assche G, Dignass A, Reinisch W. The second European evidence based consensus on the diagnosis and management of Crohn's disease: special situations. Journal of Crohn's and Colitis 2010;4:63-88.

33. Eaden J, Abrams K, Ekbom A, et al. Colorectal cancer prevention in ulcerative colitis: a case-control study. Aliment Pharmacol Ther 2000;14:145-53.

34. Rubenstein $\mathrm{JH}$, Waljee AK, Jeter JM, et al. Cost effectiveness of ulcerative colitis surveillance in the setting of 5-aminosalicylates. Am J Gastroenterol 2009;104:222232. 
Table 1 Characteristics of the study population ( $n=583)$ according to surveillance status during the study period

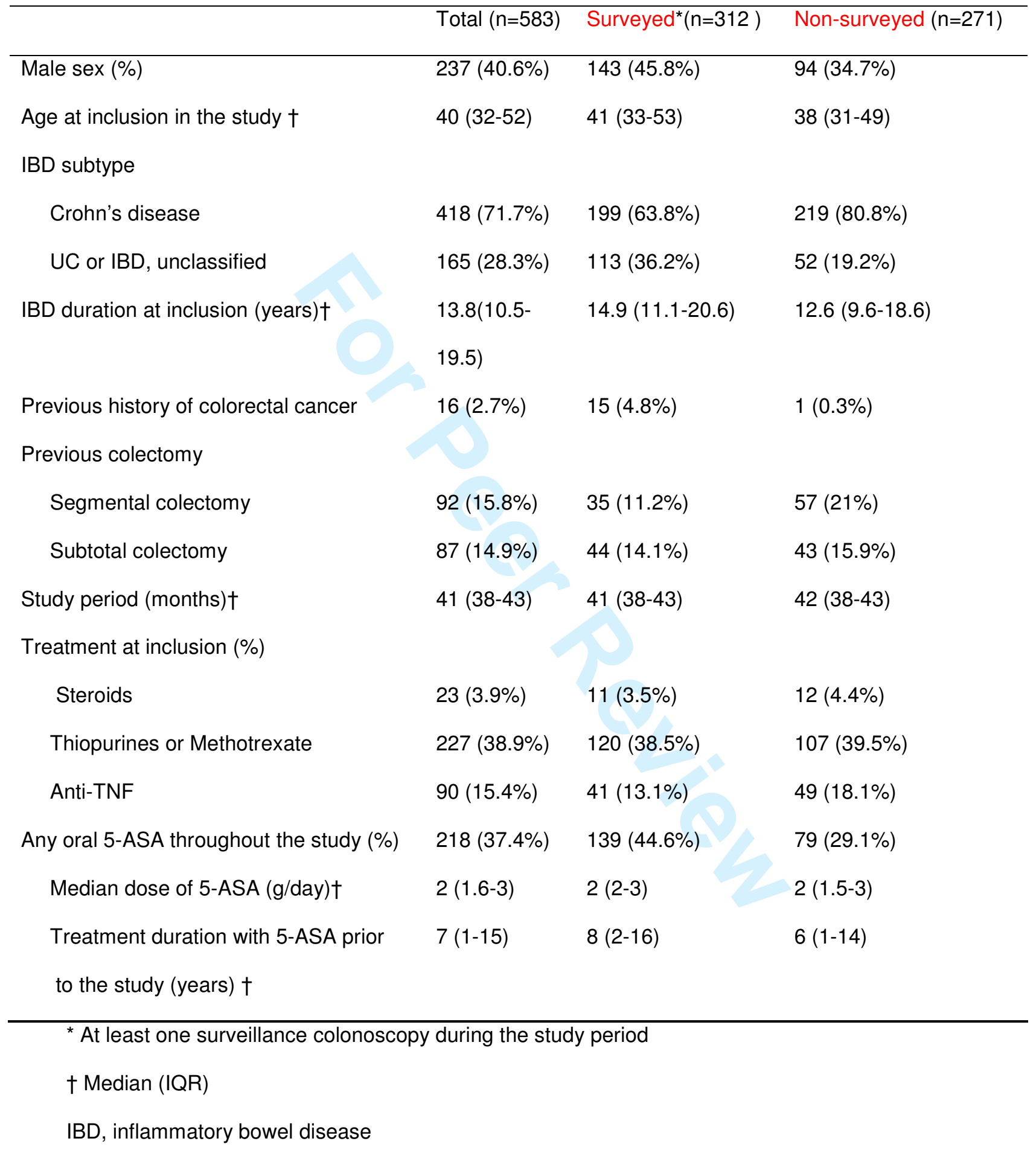


Table 2. Independent predictors of colonoscopic surveillance

\begin{tabular}{lccc}
\hline & Odds ratio & $95 \% \mathrm{Cl}$ & $\mathrm{p}$ \\
\hline Male sex & 1.60 & $1.12-2.27$ & 0.009 \\
IBD subtype: UC+ IBDu & 2.13 & $1.41-3.22$ & 0.0003 \\
$\begin{array}{l}\text { IBD duration at CESAME inclusion (per } \\
\text { additional year) }\end{array}$ & 1.04 & $1.01-1.07$ & 0.009 \\
$\begin{array}{l}\text { Previous history of CRC } \\
\text { Large number of patients per centre }(\geq\end{array}$ & 17.50 & $2.22-138.10$ & 0.006 \\
29 patients) & 1.89 & $1.10-3.23$ & 0.02 \\
\hline
\end{tabular}


Table 3. Distribution of the study population ( $n=583$ ) according to colonoscopic surveillance status and treatment with any oral 5-ASA throughout the study period

\begin{tabular}{ccccccc}
\hline & \multicolumn{2}{c}{ All patients $(\mathrm{n}=583)$} & UC or IBD, unclassified $(\mathrm{n}=165)$ & \multicolumn{2}{c}{ Crohn's colitis $(\mathrm{n}=418)$} \\
\hline & $\begin{array}{c}\text { Surveyed } \\
(\mathrm{n}=312)\end{array}$ & $\begin{array}{c}\text { Non-surveyed } \\
(\mathrm{n}=271)\end{array}$ & $\begin{array}{c}\text { Surveyed } \\
(\mathrm{n}=113)\end{array}$ & $\begin{array}{c}\text { Non-surveyed } \\
(\mathrm{n}=52)\end{array}$ & $\begin{array}{c}\text { Surveyed } \\
(\mathrm{n}=1 \mathrm{1})\end{array}$ & $\begin{array}{c}\text { Non-surveyed } \\
(\mathrm{n}=219)\end{array}$ \\
5-ASA (\%*) & $139(23.8 \%)$ & $79(13.6 \%)$ & $76(46.1 \%)$ & $22(13.3 \%)$ & $63(15.1 \%)$ & $57(13.6 \%)$ \\
No 5-ASA (\%) & $173(29.7 \%)$ & $192(32.9 \%)$ & $37(22.4 \%)$ & $30(18.2 \%)$ & $136(32.5 \%)$ & $162(38.8 \%)$ \\
\hline
\end{tabular}

* Percentages refer to the total of patients with the IBD subtype 
Figure 1

10 pts died

34 addresses lacking

910 patients (pts) eligible

19 pts refused to participate 162 pts did not answer

102 pts with previous coloproctectectomy
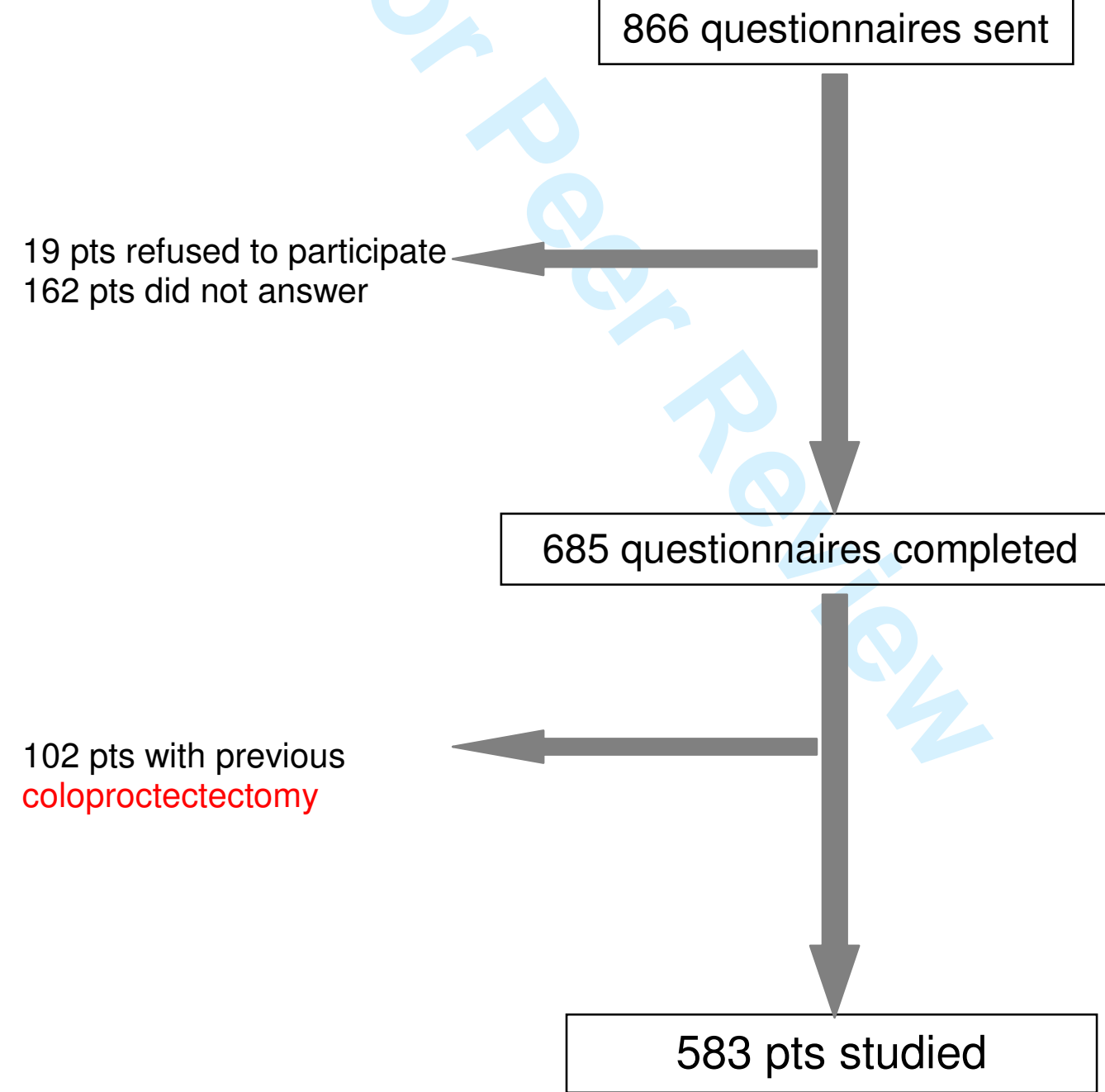
Figure 2

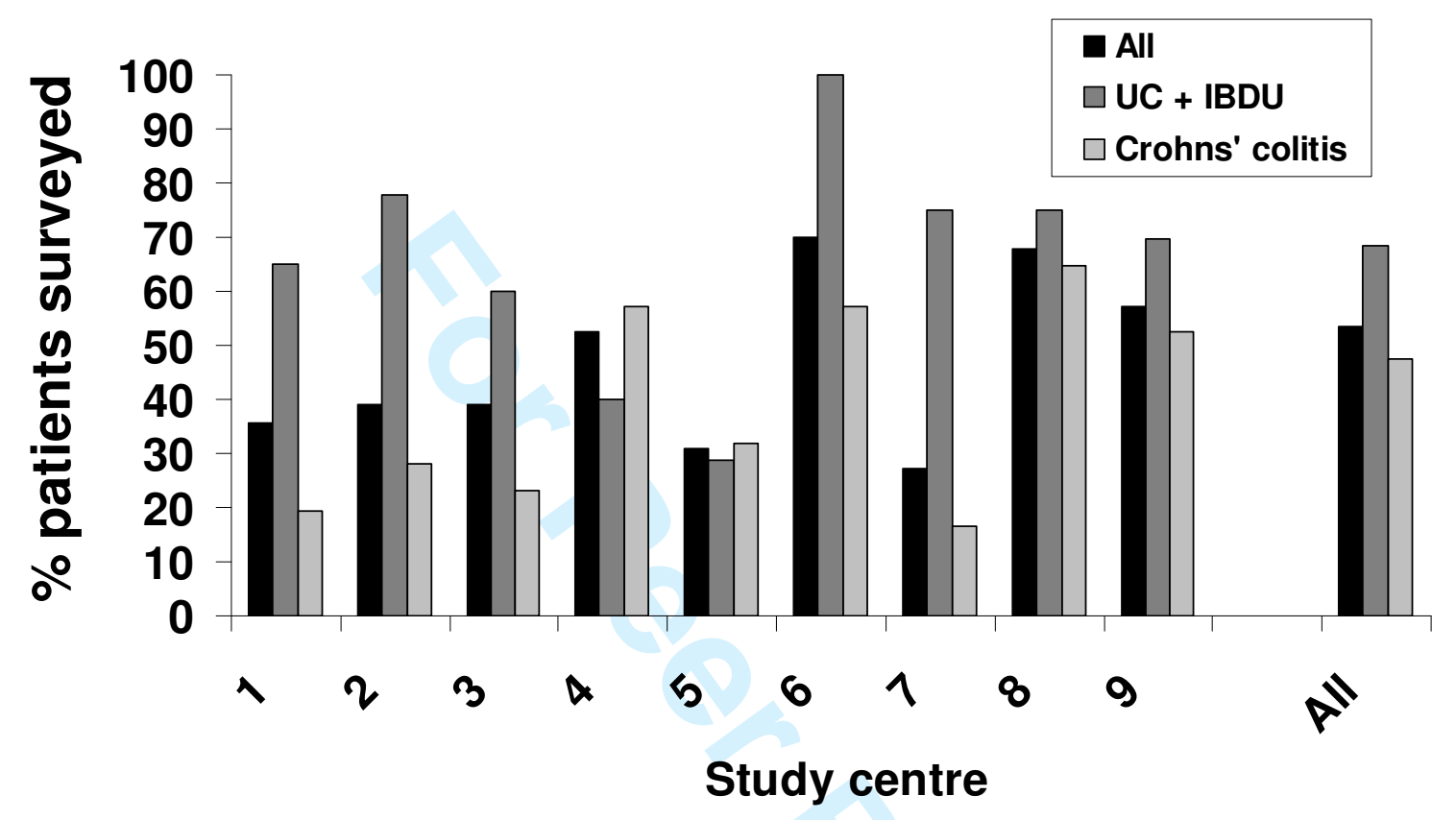




\section{EDITOR'S COMMENTS TO AUTHOR:}

Very interesting (and worrying study). It would be interesting to know what "corrective measures" you would propose to implement.

Consider adding in the discussion a paragraph about strength and weaknesses of the study.

We added some suggestions for "corrective measures" in the last paragraph of the discussion. We also added two paragraphs in the discussion (second and third

paragraph) considering the weaknesses and strengths of the work.

\section{REVIEWERS' COMMENTS TO AUTHOR:}

Reviewer: 1

Comments for Transmission to the Authors

Although AP\&T discourages a geographical location in the Title, I think the country of the study should be mentioned in the Summary.

Done

AP\&T has a specific style for the Summary: Background, Aim, Methods, Results, Conclusions - all in $<250$ words.

Done

In the past few years, AP\&T has published several relevant papers about colonoscopy, which could augment the Discussion.

Two interesting papers from AP\&T are now cited in the discussion

Reviewer: 2

Comments for Transmission to the Authors

In the present study the authors assessed modalities and results of colonoscopic surveillance in a subset of CESAME cohort patients at high risk of CRC.

The issue is an interesting one. Nevertheless, the main bias of the study is represented by the observation that a high proportion of patients were excluded from the analysis and that reports of colonoscopies were available only for a proportion of patients The following major and minor issues should be addressed before acceptance of the manuscript.

\section{Major comments}

1. Study Population. Table 1 clearly shows that UC and CD patients were differently represented among monitored and unmonitored patients. In particular, in CD there was a higher proportion of unmonitored patients $(81 \%)(p=$ ?). Moreover, the monitoring rate was higher in UC vs CD ( $p<0.0001)$ (pag. 10). This different distribution of patients may not allow proper comparison between CD and UC. Please discuss this finding.

We are not sure to have understood the reviewer's comment. May be there was an ambiguity in the "monitored" term so we replaced it by "surveyed". Regarding the completion rate of the questionnaire, there was no difference between Crohn's disease and ulcerative colitis. Among the patients finally studied, the surveillance rate was higher in ulcerative colitis than in Crohn's colitis, which is an important result of the study. The univariate statistical test was given in the text of the result section of the original version (first sentence of the paragraph entitled "factors influencing surveillance"). The role of the other factors on the surveillance rate was assessed by 
multivariate analysis (Table 2), which is the appropriate method to assess the independent individual impact of other factors

2. The proportion of patients assuming any oral 5-ASA was also higher in monitored vs unmonitored patients (44.6\% vs $29.1 \% ; p=$ ?). This observation may also influence the rate of dysplastic/neoplastic lesions: please discuss this issue. The reviewer is right. We wrote in a dedicated paragraph of the result section of the original manuscript that "There was a significant link between surveillance and treatment with 5-ASA $(p=0.0001)$, with a trend towards being either both surveyed and treated with 5-ASA, or non-surveyed and untreated." The number of incident neoplasias according to the exposure status to 5-ASA is now given in the revised version of the manuscript. But we think that the influence of exposure to 5-ASA o the incidence of neoplastic lesions cannot be properly assessed statistically given the low number of events.

3. Methods: page 7: 910 patients who met criteria were sent a questionnaire covering several items regarding clinical characteristics of the disease. The bias of a retrospective analysis reported in a questionnaire should be reported and discussed. Patients excluded for previous coloproctectomy were not eligible for the study (no colon, no surveillance), so this exclusion did not impact on the quality of the results. The questionnaire completion rate was about $80 \%$ and there was no difference in the completion rate according to IBD subtype (Method section). The memory bias is a potential important one, but we had the opportunity to cross-validate self-reporting data in the majority of the patients through the access to endoscopic reports. This is discussed in the revised paper in the second and paragraph of the discussion.

4. The major bias of the study is represented by the retrospective analysis of the data and by the high rate of patients excluded from the analysis (from 910 to 583 patients). Moreover among these 583 patients, endoscopic reports were obtained only for 440 colonoscopies performed in 270 patients. Details of colonoscopy (including bowel preparation, reported only in $82 \%$ pts with endoscopic reports, coecal intubation, etc were therefore missing in a high proportion of patients). Please comment on that in the discussion.

5. The number and site of the biopsies differed among patients, thus leading to possible differences in terms of diagnosis of dysplasia. Please comment on that. 4 and 5. Our study was focused on the prevalence of the surveillance and the identification of the factors associated with a low rate of surveillance. The reviewer is right to point the incomplete data collection in the section of the work devoted to the modalities of colonoscopies. So we chose not to speculate in the result or in the discussion section on the relationship between colonoscopy modalities and incidence of dysplastic lesion. In addition, the number of events was too low to perform an accurate analysis.

\section{Minor comments}

1. Figure 1: excluded due to "previous proctocolectomy" and not "colectomy", please modify (page 8). 
2. The percentage of patients not reporting the questionnaire but replying only by telephone should be reported in the results section and also discussed.

The number of patients contacted by phone was added in the revised manuscript. The questionnaire of the paper version and of the phone call was the same and the validity of declarative data is discussed in the second paragraph of the discussion.

3. Results regarding the detection of dysplasia (page 11) should be also reported in patients monitored vs unmonitored and in patients with vs without 5-ASA treatment. In the non-surveyed (non-monitored) patients, only colorectal cancers were diagnosed. In the surveyed patients with incident dysplasia, we added the information on the proportion of patients exposed to 5-ASA.

4. Please provide clinical details of patients developing colorectal cancer and dysplasia (age, disease duration, use of 5-ASA, disease extent).

We provide in the revised version clinical details in all the patients who developed colorectal cancer or high-grade dysplasia.

Reviewer: 3

Comments for Transmission to the Authors

Beaugerie and colleagues performed a nested study within the CESAME cohort to assess use of surveillance colonoscopy in long-standing (>7 years) colitis (CD and UC). They

found that a significant number of pts did not have "adequate" surveillance. This analysis is of interest, not just because of the importance of the CESAME cohort and follow-up, but also because it contributes to the understanding that physicians are not performing surveillance as recommended in guidelines. The statement that the surveillance is "suboptimal" might be stretching it a bit, as we don't actually know what "optimal" surveillance really is - from a mortality benefit.

Additional strengths of the study includes that it reflects practice within the northern France gastro community, with a very high response rate to the surveys. In addition, there was a high degree of correlation b/w survey responses and chart review.

The concerns I raise include the following:

1. Can you really conclude that surveillance was "suboptimal" based on these results? I would suggest what you've shown is that surveillance is not following accepted guidelines in many patients, but to call it suboptimal suggests you've actually shown a significant difference in outcomes, which I don't think you have. If you were going to assess differences in outcomes of the monitored and unmonitored groups, you need to control for risks of neoplasia, including degree of inflammation, which is not captured in this database. Therefore, l'd suggest softening the conclusions and the title to more accurately reflect what is shown here- that guidelines are infrequently followed.

The reviewer is right. We replaced the term "suboptimal" with the more neutral term "low prevalence of".

2. What were the reasons for colectomy in the 102 patients who were eligible for this 
study but couldn't participate? Were any of these due to dysplasia or cancer? If so, that would suggest that there may be a survival bias or that the approach to surveillance is more effective than acknowledged.

Unfortunately, the indication of the proctocolectomy was not an item of the survey so we have not this information.

3. you refer to the patients on 5- ASA as having been "prescribed" chemoprevention. Was that really the reason for it, or are you assuming so, but actually the 5-ASA was being given for treatment? Consider modifying this language. The reviewer is right. We have no data on the indication of the treatment with 5-ASA. We replaced the terms "chemoprevention" and "prescription" by "treatment with" and "exposition".

4. The group with previous colorectal cancer is of interest - if UC, would presume that they had a proctocolectomy, so what exams were they receiving?? If CD, would suspect that the area of colitis was resected in such patients, so perhaps they should not have inflammation any longer (and might not undergo the usual surveillance)? l'd suggest excluding these

patients from your analysis given the potential biases that they may cause.

Patients with previous proctocolectomy were excluded from this work. The 14 patients with previous colorectal cancer (11 Crohn, 3 UC) had a segmental colectomy or a subtotal colectomy with subsequent surveillance of the remaining segments. They were better surveyed than the rest of the patient population (Table 3), which is an interesting result. As we performed a multivariate analysis for assessing the other factors, we are not sure that exclusion of patients with previous cancers is appropriate.

5. would be interesting to see the survey- perhaps as an online appendix The original survey was uploaded beside the manuscript.

6. the gender differences (Males surveyed more than females) is fascinating and I appreciate the discussion. Why? was their disease more active? is that what drove this? (some gender based studies have shown that males are less likely to get mucosal healing and other studies have shown that males are at higher risk for cancer).

We extended speculation and references on male predominance to other contexts of colonoscopic surveillance. 


\title{
Alimentary Pharmacology \& Therapeutic

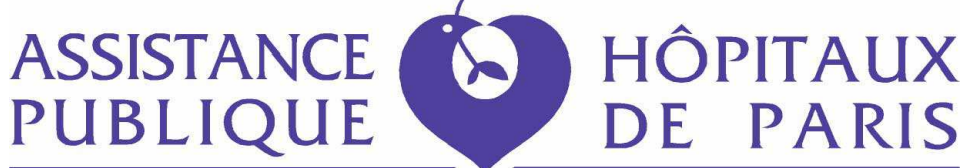

\section{SEC C I R C \\ ENQUETE DE PRATIQUE DE LA COLOSCOPIE DANS LES MICI \\ NUMERO D'ANONYMAT}

\begin{abstract}
Vous vous apprêtez à répondre à un questionnaire dans le cadre d'une enquête sur la réalisation des coloscopies dans les MICI (Maladies Inflammatoires Chroniques de l'Intestin).

Un grand MERCI pour votre collaboration.
\end{abstract}

Pour toutes les questions suivantes, merci d'entourer la ou les réponses vous concernant:

A. De quel type de maladie inflammatoire de l'intestin souffrez-vous ?

0. Je ne sais pas

1. Recto-colite hémorragique $(\mathrm{RCH})$

2. Maladie de Crohn

3. Colite inflammatoire sans que l'on sache s'il s'agit d'une maladie de Crohn ou d'une $\mathrm{RCH}$

B. Avez-vous déjà été opéré du côlon (gros intestin)

0. non, jamais

1. oui

C. * Si vous avez déjà été opéré du côlon (gros intestin), quel type d'opération avezvous eue?

0. on a enlevé tout le côlon et le rectum avec une anastomose iléo-anale et la confection d'un réservoir avec l'intestin grêle

1. on a enlevé tout le côlon et le rectum avec une poche définitive

2. on a enlevé tout le côlon mais pas le rectum

3. on a enlevé seulement une partie du côlon

4. je ne sais pas

* Si vous avez répondu 2,3 ou 4 à la question précédente $\boldsymbol{C}$, merci de répondre aux questions suivantes :

* Si vous avez répondu $\mathbf{0}$ ou 1 à la question précédente $\boldsymbol{C}$ (ablation totale du côlon et du rectum), la question de la réalisation de coloscopies ne se pose pas de la même façon chez vous, il n'est donc pas nécessaire que vous répondiez aux questions suivantes. Merci d'avoir pris le temps de remplir et de nous renvoyer malgré tout ce questionnaire. 
D. Quel(s) traitement(s) recevez vous actuellement ? (plusieurs réponses possibles, entourez les réponses exactes)

0 . Je ne reçois actuellement aucun traitement

1. Comprimés (ou gélules ou granulés) de dérivés 5 aminosalicylés (5ASA) : Pentasa, Rowasa, Dipentum, Fivasa ou Salazopyrine

2. Lavements de Pentasa ou de Quadrasa

3. Suppositoires de Pentasa, Rowasa, ou Fivasa

4. Comprimés de Cortisone : solupred, cortancyl, prednisone ou prednisolone

5. Imurel, Azathioprine, Purinethol, Méthotrexate

6. Remicade, Humira, Cimzia

7. Autre traitement pour la MICI: lequel

E. Si vous êtes actuellement traité par comprimés (ou gélules ou granulés) de Pentasa, Rowasa, Dipentum, Fivasa ou Salazopyrine, depuis quand prenez vous ce traitement de façon continue ? (mois et année ou année seule si vous ne vous souvenez pas du mois)

0. Date de début du traitement..............

1. Je ne sais pas

F. Si vous êtes actuellement traité par comprimés (ou gélules ou granulés) de Pentasa, Rowasa, Dipentum, Fivasa ou Salazopyrine, quelle dose prenez-vous chaque jour?

dose : (grammes/jour) $\ldots \ldots \ldots \ldots \ldots \ldots$

G. Avez-vous eu des coloscopies entre le 01/05/2004 et la réception de ce courrier:
0 . non
1. oui, une seule coloscopie
2. oui, 2 coloscopies
3. oui, plus de 2 coloscopies

Concernant les coloscopies réalisées entre le 01/05/2004 et la réception de ce courrier, merci de répondre aux questions suivantes dans le tableau ci-joint en mettant une croix dans la (ou les) case(s) correspondant à votre cas, comme dans l'exemple.

Merci de nous renvoyer ce questionnaire rempli à l'aide de l'enveloppe T ci jointe.

Vous pouvez également nous adresser ces éléments par fax au

Si vous avez des difficultés ou que vous préférez répondre à ce questionnaire par téléphone, n’hésitez pas à nous appeler sur le numéro suivant : 01-49-28-22-02 afin que l'on puisse le remplir avec vous par téléphone.

Afin de préserver votre anonymat, toutes les données vous concernant seront rendues anonymes

En vous remerciant du temps que vous nous avez consacré, soyez assuré(e), Madame, Monsieur, de nos sentiments les plus cordialement dévoués. 


\section{S E C C I R C}

ENQUETE DE PRATIQUE DE LA COLOSCOPIE DANS LES MICI NUMERO D'ANONYMAT

\begin{tabular}{|c|c|c|c|c|c|c|}
\hline & & Exemple & Coloscopie $\mathrm{N}^{\circ} 1$ & Coloscopie $\mathrm{N}^{\circ} 2$ & Coloscopie $\mathrm{N}^{\circ} 3$ & Coloscopie $\mathrm{N}^{\circ} 4$ \\
\hline $\begin{array}{l}\text { Date de la coloscopie } \\
\text { * }\end{array}$ & $\mathrm{jj} / \mathrm{mm} /$ aaaa & $01 / 05 / 2004$ & & & & \\
\hline \multirow{3}{*}{ Lieu de la coloscopie } & Hôpital "nom de 1'hôpital" & $\mathrm{X}$ & & & & \\
\hline & $\begin{array}{l}\text { examen réalisé dans un autre établissement } \\
\text { (autre hôpital ou cabinet privé) }\end{array}$ & & & & & \\
\hline & je ne sais plus & & & & & \\
\hline \multirow{4}{*}{ Raison de l'examen } & poussée & & & & & \\
\hline & bilan avant changement de traitement & $\mathrm{X}$ & & & & \\
\hline & dépistage & & $>>$ & & & \\
\hline & je ne sais pas & & 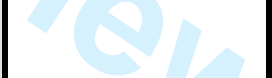 & & & \\
\hline \multirow{4}{*}{ Type de préparation } & $\begin{array}{c}\text { PEG: Kleanprep, Fortrans, Colopeg, Moviprep, } \\
\text { Biopeg }\end{array}$ & $\mathrm{X}$ & & & & \\
\hline & Xprep & & & & & \\
\hline & Fleetphosphosoda & & & & & \\
\hline & je ne sais pas & & & & & \\
\hline
\end{tabular}

* Pour la date des coloscopies, si vous ne vous rappelez pas la date précise, merci de nous donner l’année et le mois 